\title{
1 PREVENÇÃO DO SUICÍDIO: UMA TAREFA DE TODOS!
}

| José Carlos Santos ${ }^{1}$

Anualmente estima-se que morram por suicídio mais de 800000 pessoas, com uma taxa global de cerca de 11,6 por 100000 habitantes (WHO, 2014). Com assimetrias a nível global, na Europa é possível marcar uma linha entre os países de leste, com taxas superiores a 30, os países escandinavos com taxas inferiores, a rondar os 20 mas superiores à média europeia e depois dos países do sul com taxas inferiores a 10 (WHO, 2018). Portugal tem tido, nos últimos anos taxas globais superiores a 10, sendo de 10,9 para 2015 enquanto a taxa padronizada foi de 8,2, com uma oscilação entre 3,3 nos adolescentes a 30,8 nos idosos com 75 e mais anos, chegando a 59,7 nos homens nesta faixa etária. As mulheres, em Portugal, morrem por suicídio cerca de 4 vezes menos que os homens (INE, 2018).

Prevenir os comportamentos suicidários é uma das prioridades da Organização Mundial de Saúde e um compromisso assumido pelos países que a integram, visando reduzir as taxas em 10\% no ano de 2020 (WHO, 2014). Contudo, uma análise dos números disponíveis demonstra que essa não tem sido a tendência na maior parte dos países, Portugal incluído (embora registe uma diminuição no número total de suicídios no ano de 2016). Fenómeno inquietante, se atendermos à redução conseguida noutras áreas da saúde, tradicionalmente líderes em número de óbitos.

Os dados referentes à tuberculose, cancro, doença cardíaca e acidentes vasculares cerebrais têm registado um declínio acentuado, nas últimas décadas, nas taxas de óbitos, paralelamente a um aumento da esperança de vida de cerca de 30 anos (Remington \& Brownson, 2016).

Esta diminuição no número de mortes não se deveu, em nenhum caso relatado, a uma única dimensão nem tão pouco a fatores exclusivamente de saúde mas também (sobretudo?) de ordem social e estilos de vida.

Talvez fosse importante refletir porque não se tem conseguido reduzir, ao nível global, substancialmente, os comportamentos suicidários e analisar algumas experiências de sucesso.
Sendo o comportamento suicidário um fenómeno complexo e multifacetado uma intervenção individual poderá, eventualmente, adiar o comportamento mas terá maiores dificuldades de sucesso dadas as variáveis envolvidas onde emergem as determinantes de saúde. Assim, uma abordagem ecológica consciente da presença de vários níveis de influência em que estes são interactivos e se relacionam (Golden \& Earp, 2012) terá maiores probabilidades de sucesso na diminuição do número de comportamentos suicidários. De resto, alguns exemplos com o foco na população e uma abordagem ecológica que promova o bem-estar mental e a resiliência para toda a comunidade parecem ser mais efectivos que os programas centrados no risco (Cutcliffe, Wylie, Links \& Santos, 2017).

Para isso, a produção da melhor evidência necessita de ser incentivada, validada, partilhada para que possamos utilizá-la de forma eficaz. A investigação em suicidologia tem conhecido maior atenção dada a diversidade de estudos e disciplinas envolvidas. Apesar disso ainda é necessário reforçar a colocação da investigação em suicidologia na agenda quando falamos de prioridades nacionais e planos de financiamento.

Têm sido registados avanços importantes, particularmente na área das neurociências, mas a procura continua incompleta na busca de respostas a duas questões básicas: como se desenvolve o processo suicida e o que podemos fazer para a sua prevenção. $\mathrm{Na}$ procura de respostas a estas duas questões todas as disciplinas do conhecimento, onde a enfermagem está obviamente incluída, são chamadas a contribuir para uma resposta global.

Mas de pouco adiantará haver respostas ao nível da investigação e produção de conhecimento se, na prática, continuarmos afastados das melhores evidências disponíveis.

1 Doutor em Saúde Mental; Mestre em Sociopsicologia da Saúde; Enfermeiro especialista em Enfermagem de Saúde Mental e Psiquiátrica; Professor Coordenador na Escola Superior de Enfermagem de Coimbra, Rua 5 de Outubro, 3046-851 Coimbra, Portugal. E-mail: jcsantos@esenfc.pt 
Assim, a translação do conhecimento assume-se como uma prioridade, o que implica maior acessibilidade, maior consciencialização dos políticos e/ou gestores, maior responsabilidade dos profissionais de saúde e/ou cuidadores e, por último, maior exigência de qualidade por parte de todos os cidadãos.

Porquê? Porque o comportamento suicida, apesar de permanecer em muitas nuances, $o$ ato mais misterioso do ser humano, é possível evitá-lo quando se aposta, de uma forma multidisciplinar e multissectorial, na sua prevenção.

E os enfermeiros de saúde mental? Talvez, sempre que incorporam uma filosofia humanista dos cuidados, uma visão sistémica e uma intervenção ecológica se constituam como elementos fundamentais, num contexto multidisciplinar, para a prevenção de comportamentos suicidários.

\section{REFERÊNCIAS BIBLIOGRÁFICAS}

Cutcliffe, J., Wylie, L., Links, P., \& Santos, J. (2017). Adopting an ecological public health approach to suicide prevention - the cases of Turkey and Canada: Why can't we get there?. Journal of Psychiatric Nursing, 8(3), 172-178. doi: 10.14744/phd.2017.40327
Golden, S., \& Earp, J. (2012). Social ecological approaches to individuals and their contexts: Twenty years of health education \& behavior health promotion interventions. Health Education \& Behavior, 39(3), 364-372. doi: 10.1177/1090198111418634

Instituto Nacional de Estatística. (2018). Taxa de mortalidade por lesões autoprovocadas intencionalmente (suicídio) por 100000 habitantes. Lisboa: Instituto Nacional de Estatística.

Remington, P. L., \& Brownson, R. C. (2016). Morbidity and Mortality Weekly Report (MMWR): Fifty years of progress in chronic disease epidemiology and control. Center for Disease Control and Prevention, 60(4), 70-77.

World Health Organization. (2014). Preventing suicide: A global imperative. Geneva: World Health Organization.

World Health Organization. (2018). World Health Statistics data visualization dashboard. Geneva: World Health Organization.

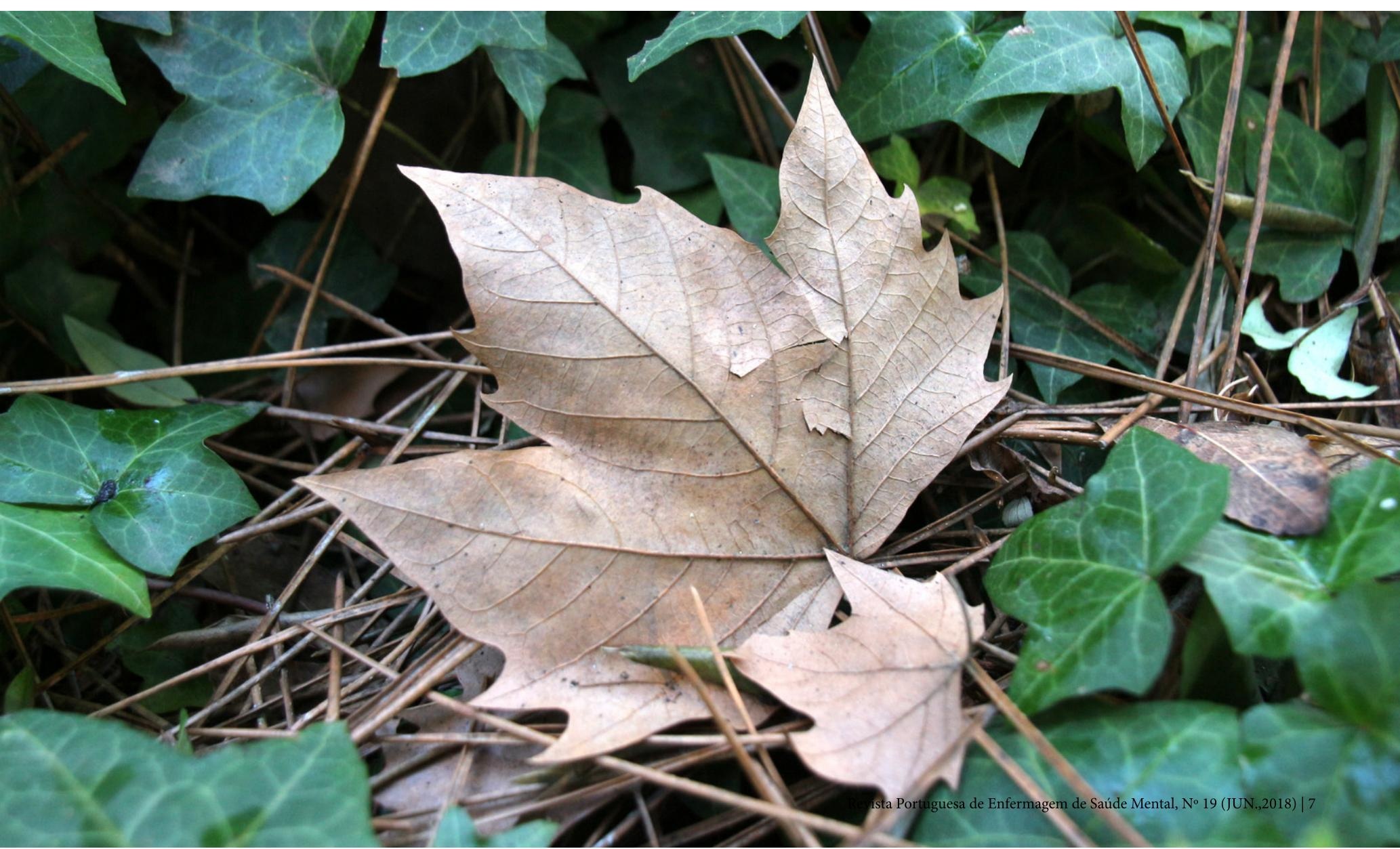

